\title{
Effect of deposition potential and copper concentration on the phase transformation mechanism and structural distribution during electrodeposition of $\mathrm{Ni}-\mathrm{Cu}$ magnetic alloy thin films
}

\author{
P. Nath, R. Pandey, A. Das, A. Mallik* \\ Electrometallurgy and Corrosion Lab., Department of Metallurgical and Materials Engineering, \\ National Institute of Technology, Rourkela 769008, Odisha, India
}

Received 17 May 2016, received in revised form 29 September 2016, accepted 30 September 2016

\begin{abstract}
$\mathrm{Ni}-\mathrm{Cu}$ alloy thin films were electroplated onto graphite substrates in three electrode setup at varying applied overpotentials of $-1.4,-1.5$, and $-1.6 \mathrm{~V}$ with an approximate $\mathrm{Cu}$ : Ni ratio of $1: 20,1: 15$, and $1: 11$ where the concentration of $\mathrm{Ni}$ was $0.175 \mathrm{M}$, and $\mathrm{Cu}$ were $0.009 \mathrm{M}$, $0.012 \mathrm{M}, 0.015 \mathrm{M}$, respectively. The cyclic voltammetry experiments reveal that during the co-reduction of $\mathrm{Cu}$ and $\mathrm{Ni}$ there was no distinct peak. However, the dissolution had taken place with absolute anodic peaks for corresponding elements. Morphological results showed there was a transition from wavy layered structure to the nodular structure with an increase in deposition potential and $\mathrm{Cu}$ concentration in the bath. The compositional analysis revealed that the film was getting richer in $\mathrm{Ni}$ with an increase in deposition potential and a decrease in $\mathrm{Cu}$ ion concentration in the electrolyte bath. Magnetic Force Microscopy (MFM) technique indicated that there was a definite and distinct impact of deposition potential and composition on the distribution of magnetic phase in the alloy film.
\end{abstract}

K e y w o r d s: Ni-Cu alloy, thin film, Magnetic Force Microscopy (MFM), electrodeposition, cyclic voltammetry

\section{Introduction}

Magnetic thin films either single layer or multilayer are showing increasing potential nowadays because of their unique properties. Thin film alloys show totally different magnetic properties compared to their bulk counterpart $[1,2]$. These thin films are extensively used in the fabrication of microelectromechanical systems [MEMS], micro-inductors, actuators and sensors, hard disk drives [HDD], magnetic recording media [3-5]. Magnetic domain structure is responsible for the magnetic behaviour of ferromagnetic materials like iron, cobalt, nickel, and their alloys [6]. A magnetic domain is a region inside a magnetic material in which the magnetic fields of atoms are grouped together and aligned [7]. The regions separating magnetic domains are called domain walls. Hence the study of molecular structures of the magnetic thin films may lead to data storage on the nanometer scale and a better understanding of the fundamental limits of magnetic data storage devices.

Due to its ferromagnetic properties, $\mathrm{Ni}$ and its alloy thin films have been widely researched and used in the applications mentioned above. However, the only demerit is that they do not possess low coercive value. So the addition of $\mathrm{Cu}$ was found to be beneficial to decrease the coercivity and increase the corrosion resistance of the film. Moreover, $\mathrm{Ni}-\mathrm{Cu}$ system is one of the most studied topics since $\mathrm{Ni}$ and $\mathrm{Cu}$ have an identical crystal structure and nearly the same lattice parameters [8-11]. There are many vacuum based vapour phases as well as chemical techniques which are being practized for the synthesis of these magnetic thin films. However, the common drawbacks of these techniques are due to their high cost, high energy requirement, treatment of gaseous wastes, and handling of a hazardous chemical. Conversely, electrodeposition stands out from the rest of the techniques because it is simple, fast, and cost-effective. It can be done

${ }^{*}$ Corresponding author: tels.: +91-6612462558(O), +91-6612476361(R); fax: +91-6612462999;

e-mail addresses: archananitrkl@gmail.com, archanam@nitrkl.ac.in 
at room temperature and pressure. The particle size, crystallographic orientation, thickness, and morphology of thin films can be easily modified by controlling the bath chemistry and various deposition parameters $[12,13]$. The concentrations of bath and operating conditions (current density, potential, $\mathrm{pH}$ ) have a direct influence on the stoichiometry, composition, microstructure, and surface morphology of $\mathrm{Ni}-\mathrm{Cu}$ alloy films. Increase in Ni-ion concentration [10], current density [14], and deposition potential [15] were found to increase the nickel content in the alloy films. With the increase in $\mathrm{Ni}$ content of the film the saturation magnetization [9] of $\mathrm{Cu}-\mathrm{Ni}$ films increases and a transition from paramagnetic to ferromagnetic behaviour is seen $[9,16]$. The deposition process also gets affected by the $\mathrm{Ni} / \mathrm{Cu}$ ratio in the electrolyte. $\mathrm{Cu}$ content of the film increases with an increase in $\mathrm{Cu}$ concentration in the electrolyte. Furthermore, with an increase in $\mathrm{Cu}$ content and a decrease in electrolyte $\mathrm{pH}$ [17] the surface roughness of the $\mathrm{Ni}-\mathrm{Cu}$ alloy films increases $[18$, 19]. It was also found that films grown at high $\mathrm{pH}$ are harder to magnetize compared to those at low $\mathrm{pH}$ [8]. Hence there is ample scope to study the effect of deposition potential and concentration to synthesize the films and manipulation further to the sought required applications.

There are many techniques by which we can do the magnetic characterization [20-23]. Among all the available methods to characterize magnetic properties, magnetic force microscopy (MFM) is the least explored and could be the most potent one if explored extensively. It could provide an internal structure of the domain, domain walls and magnetic spin distribution within it [24]. MFM uses both magnetic force and Van der Waals force during characterization so one can get information about both surface topography and surface magnetic properties. The authors have also reported an analysis on the effect of ultrasound on the magnetic topography of electroplated $\mathrm{Ni}$ films by Magnetic Force Microscopy (MFM) [24].

Hence the present investigation is focused on the deposition thermodynamics and kinetics of the phase transformation phenomena and variation of the composition of the $\mathrm{Cu}-\mathrm{Ni}$ alloys, morphology, and magnetic structure with electrolyte composition and applied potential to the working graphite electrode.

\section{Experimental}

The electroplating bath for $\mathrm{Ni}-\mathrm{Cu}$ alloy contained $0.175 \mathrm{M} \mathrm{NiSO}_{4} \cdot 6 \mathrm{H}_{2} \mathrm{O}, 0.46 \mathrm{M} \mathrm{H}_{3} \mathrm{BO}_{3}$ and different concentrations of $\mathrm{CuSO}_{4} \cdot 5 \mathrm{H}_{2} \mathrm{O}(0.009,0.012$, and $0.015 \mathrm{M})$ to maintain an approximate $\mathrm{Cu} / \mathrm{Ni}$ concentration ratio of $1: 20,1: 15$, and $1: 11$, respectively. All the chemicals were of analytical grade and solutions were freshly prepared with double distilled water. The electrochemical measurements were performed in a conventional three-electrode cell using Potentiostat/Galvanostat (Autolab PGSTAT 12) equipment interfaced with GPES software. The working electrode was a flat graphite bar (Asbury, USA) with an exposed area of $0.0625 \mathrm{~cm}^{2}$. The reference electrode was $\mathrm{Ag} / \mathrm{AgCl}$, and the counter electrode was also a graphite bar (Asbury, USA) of larger surface area than the cathode surface. Before each experiment graphite electrodes were polished with different grades of emery paper, then repeatedly treated with ultrasound and successively washed with distilled water and acetone for $20 \mathrm{~min}$. The electrodes were finally dried with the help of hot air blower. $\mathrm{In} \mathrm{Ag} / \mathrm{AgCl}$ electrode the reference electrolyte used was $3 \mathrm{M} \mathrm{KCl}$ having the standard potential of $207 \mathrm{mV} / \mathrm{SHE}\left(25^{\circ} \mathrm{C}\right)$. The bath temperature was maintained at $298 \mathrm{~K}\left(25^{\circ} \mathrm{C}\right)$ for all the depositions. XRD patterns were recorded from $40^{\circ}$ to $100^{\circ}$ with a Philips X-pert MPD system diffractometer using $\mathrm{Cu} \mathrm{K} \alpha$ at an accelerating voltage of $40 \mathrm{kV}$. Data was collected at a counting rate of $1^{\circ} \mathrm{min}^{-1}$. Scanning electron microscope (SEM) JEOL 6480 LV equipped with an energy dispersive X-ray detector of Oxford data reference system was used to study film morphology and composition. The roughness analysis was done by Atomic Force Microscopy (SPM Laboratory-programmed Veeco diInnova). The surface topography and magnetic measurements were taken by Magnetic Force Microscopy (MFM) in tapping mode at a lift height of $50 \mathrm{~nm}$ with a $\mathrm{Sb}(\mathrm{n})$ doped Si tip coated with $\mathrm{Co} / \mathrm{Cr} / \mathrm{BOT}-1-10 \mathrm{~nm} \mathrm{Cr}$ on both sides.

\section{Results and discussion}

\subsection{Cyclic voltammetry}

Cyclic voltammetry was studied to determine the redox couple and its kinetics for the individual metal systems ( $\mathrm{Ni}$ and $\mathrm{Cu}$ ) as well as the alloy system. Figure 1a shows the superimposed cyclic voltammograms for $\mathrm{Ni}, \mathrm{Cu}$, and $\mathrm{Ni}-\mathrm{Cu}$ alloy for the deposition and dissolution phases onto graphite substrates in different scanning ranges and at a scan rate of $10 \mathrm{mV} \mathrm{s}^{-1}$.

For nickel deposition, there was no increase of negative/reduction current until the potential reached to $-0.5 \mathrm{~V}$ vs. $\mathrm{Ag} / \mathrm{AgCl}$, which is also the crossover potential for the system. The presence of a crossover is diagnostic for the nucleation and growth phase on the electrode. At this voltage, the cathodic current started to increase and formed the reduction peak $\left(E_{\mathrm{pc}, \mathrm{Ni}}\right)$ at $-1.7 \mathrm{~V}$ vs. $\mathrm{Ag} / \mathrm{AgCl}$. Then the current increased to the vertex potential without any noticeable change, which might be ascribed to nickel deposition with simultaneous hydrogen evolution. After then, the cathodic current decreased gradually until it crossed at $0 \mathrm{~V}$ and turned into the anodic current. Upon sweep reversal, 

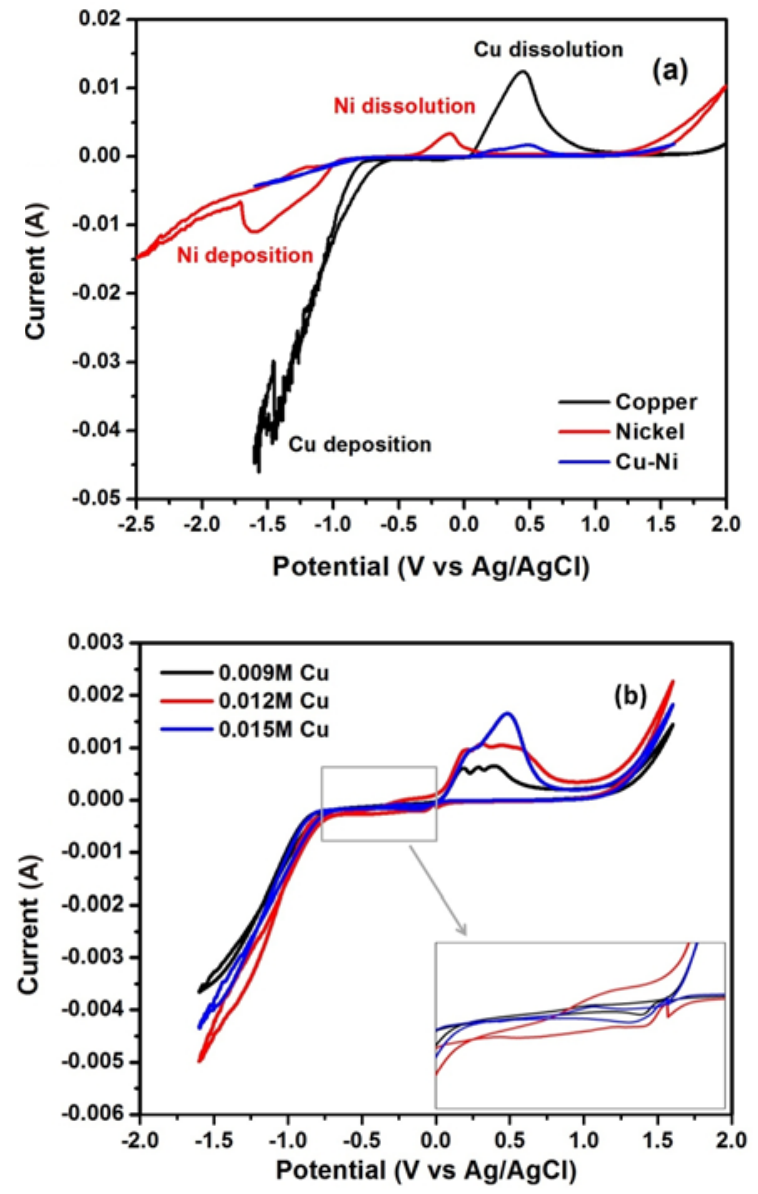

Fig. 1. Cyclic voltammograms of (a) nickel, copper, and $\mathrm{Ni}-\mathrm{Cu}$ alloy, (b) Ni-Cu alloy system at $\mathrm{Cu}$ concentration of $0.009 \mathrm{M}, 0.012 \mathrm{M}$, and $0.015 \mathrm{M}$ at $298 \mathrm{~K}\left(25^{\circ} \mathrm{C}\right)$ with a scan rate of $10 \mathrm{mV} \mathrm{s}^{-1}$.

metal already deposited on the electrode surface continued to grow as a result of the reduction of $\mathrm{Ni}^{2+}$ to $\mathrm{Ni}(\mathrm{s})$, the said reaction remaining thermodynamically and kinetically favourable. Further sweep in the positive direction resulted in the anodic peak $\left(E_{\mathrm{pa}, \mathrm{Ni}}\right)$ at $+0.158 \mathrm{~V}$ vs. $\mathrm{Ag} / \mathrm{AgCl}$ which is the dissolution peak of Ni deposition [19]. The early dissolution and delayed deposition of metal confirm the dynamic nature of the metal. The increase in current past the peak at a potential of $+1.5 \mathrm{~V}$ vs. $\mathrm{Ag} / \mathrm{AgCl}$ could be due to oxygen evolution at electrode surface (confirmed by EDS analysis but not shown here). The value of $\left(E_{\mathrm{pc}, \mathrm{Ni}}-E_{\mathrm{pa}, \mathrm{Ni}}\right)$ is greater than $70 \mathrm{mV}$, indicating that the nucleation and growth phase kinetics might have followed a mixed mass and charge controlled (quasi-reversible) process. Also, the ratio of $I_{\mathrm{c}}, \mathrm{Ni}$ (the current at $\left.E_{\mathrm{pc}, \mathrm{Ni}}\right)$ and $I_{\mathrm{a}, \mathrm{Ni}}$ (the current at $\left.E_{\mathrm{pa}, \mathrm{Ni}}\right)$ is 3.27 , which may further supplement the above inference on the kinetics aspect. For copper, there is no distinct reduction peak; however, there is an increase of cathodic current with the increase of negative bias.
This, of course, is due to the evolution of hydrogen at such high overpotential as copper cannot have a distinct reduction peak at such low copper ion concentration of the solution. Upon reversing the direction of the current, the crossover potential formed at the potential of $+0.17 \mathrm{~V}$ vs. $\mathrm{Ag} / \mathrm{AgCl}$. However, there is a very distinct anodic peak around $+0.5 \mathrm{~V}$, which might be either due to oxidation of water to oxygen or intercalation of anions into the graphite substrate at such high temperature.

Cyclic voltammograms for $\mathrm{Ni}-\mathrm{Cu}$ alloy for the deposition and dissolution phases onto graphite substrate at the scanning range of -1.6 to $+1.6 \mathrm{~V}$ at a scan rate of $10 \mathrm{mV} \mathrm{s}^{-1}$ in different $\mathrm{Cu}$ concentration solution are shown in Fig. 1b. The alloy has got reduced without any reduction peak and has consumed less charge than any of the individual components, i.e. $\mathrm{Ni}$ and $\mathrm{Cu}$. This may be an indication of steady and irreversible incorporation of the metals in the alloy lattice during metal discharge. There are no remarkable differences in the reduction peaks at different $\mathrm{Cu}$ concentration. However, there is a shift of dissolution peak (anodic peak) towards more positive potential as $\mathrm{Cu}$ concentration in the alloy bath increases. This may be because of high availability of $\mathrm{Cu}$ ions in the ionic atmosphere with an increase in $\mathrm{Cu}$ concentration in the bath. Again there is an increase in the anodic peak area as the $\mathrm{Cu}$ concentration increases. We can observe from these facts that over-potential of the cathodic process is practically independent of concentration, whereas anodic peak maximum does depend upon the amount of metal reduced. It can also be observed that there are multiple anodic peaks for the alloy dissolution corresponding to the subsequent dissolution of $\mathrm{Ni}$ and $\mathrm{Cu}$. The anodic peaks are at potentials of $0.090 \mathrm{~V}, 0.196 \mathrm{~V}$, and $0.288 \mathrm{~V}$ vs. SCE for $0.009 \mathrm{M}, 0.012 \mathrm{M}$, and $0.015 \mathrm{M}$, respectively. However, for $0.015 \mathrm{Cu}$ concentrations, only one dissolution peak is present, indicating only the coupled metal dissolution reaction at the electrode surface.

To analyse the cathodic efficiency $\left(Q_{\mathrm{a}} / Q_{\mathrm{c}}\right.$ ratio $)$ of the elemental and alloy deposition, the charge due to cathodic $\left(Q_{\mathrm{c}}\right)$ and anodic $\left(Q_{\mathrm{a}}\right)$ processes can be obtained from integration of the cathodic and anodic branches of the $I-E$ curves. The $Q_{\mathrm{a}} / Q_{\mathrm{c}}$ ratio for the $\mathrm{Ni}$ deposition from the solution was found to be 0.79 . The cathodic efficiency of copper redox reactions is 0.25 . This indicates that $\mathrm{Ni}$ and $\mathrm{Cu}$ deposited during the cathodic sweep potential were not totally oxidized during the anodic scan. The $Q_{\mathrm{a}} / Q_{\mathrm{c}}$ ratio for the alloy deposition from the solution at $0.009 \mathrm{M} \mathrm{Cu}$ concentration is found to be 0.32 . Faradaic efficiency has increased to 1.07 with increasing copper concentration in the solution. This over efficiency indicates that other simultaneous reactions might have occurred at the anode surface, i.e. oxygen evolution at the anode surface. 


\subsection{Phase transformation mechanism}

During synthesis of magnetic thin films for a particular application, one should have adequate information about the influence of preparation technique and parameters on the resulting grain size and magnetic properties. Synthesis of thin films through electroplating is commenced through a technique called chronoamperometry $(\mathrm{CA})$, where either a single or multiple potential steps are applied for a particular period [25]. From a CA curve, we can affirm about the nucleation and growth mechanisms taking place throughout the electrodeposition process.

$\mathrm{CA}$ current transients are recorded for $\mathrm{Ni}-\mathrm{Cu}$ alloy at $\mathrm{Ni}$ concentration of $0.175 \mathrm{M}$ and different $\mathrm{Cu}$ concentrations $(0.009,0.012$, and 0.015$)$ and deposition over-potentials of $-1.4,-1.5$, and $-1.6 \mathrm{~V}$ which are shown in Fig. 2. The recorded CA curves have a common trend of an initial decrease in cathodic current followed by an increase and then again decrease of the same. These three regions of current behaviour are generally due to double layer charging (DLC), nucleation, and growth of the newly formed phase, respectively. The current consumption for DLC is non-faradaic in nature. A change in potential at the working electrode from its equilibrium value necessarily causes a charge imbalance across the interface which must be neutralized by rearrangement of charged species in the solution near the electrode surface. After the double layer charging, the current increases rapidly to a maximum where the two ions reduce and form the alloy nuclei at the electrode surface. Then the subsequent fall of current occurs which indicates the growth of the nuclei at the electrode surface under diffusion controlled reaction according to the Cottrell behaviour. The general behaviour of the CA curves is that as the negative overpotential increases the reduction current increases and nucleation time is shorter. However, the nucleation process at a concentration of $0.009 \mathrm{M}$ seems to be incomplete or progressing at all deposition potentials. It may indicate that the alloy deposition has much scope to attend a stoichiometric composition after a longer period of deposition. At $\mathrm{Cu}$ concentration of $0.012 \mathrm{M}$, both the nucleation and growth processes are completed, but the nucleation is longer, indicating a slow but complete occupancy of the available active nucleation sites. The films deposited at $0.015 \mathrm{M} \mathrm{Cu}$ concentration seem to be the best as the current is maximum and nucleation time is shorter, and there is still scope for further growth as the slope of the growth current is negative and not zero. Hence, the results signify nucleation time was shorter for high negative potential and high $\mathrm{Cu}$ concentration bath.

There are mainly two types of nucleation and growth mechanism: mononuclear growth (two-dimensional nucleation 2D) and polynuclear growth (threedimensional nucleation 3D). Deposition happens
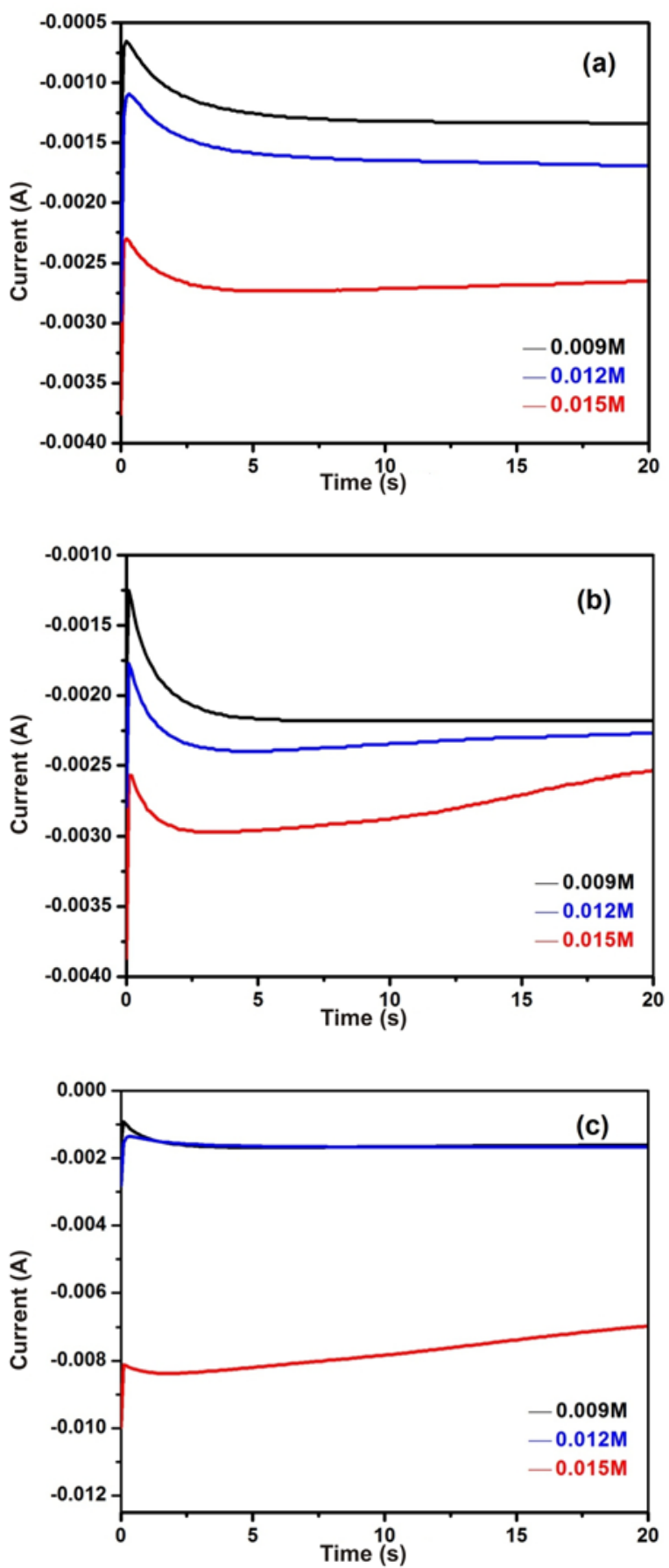

Fig. 2. Chronoamperometry of deposition of $\mathrm{Ni}-\mathrm{Cu}$ alloy thin film at (a) $-1.4 \mathrm{~V}$, (b) $-1.5 \mathrm{~V}$, and (c) $-1.6 \mathrm{~V}$ with $0.175 \mathrm{M} \mathrm{Ni}$.

through layer by layer of adatoms on the depositing plane in the case of mononuclear growth, whereas random incorporation of isolated supercritical nuclei on the substrate occurs in the case of polynuclear growth. The mode of incorporation of nuclei directly affects the magnetic moments of the atom. This nucleation process is basically of two types: instantaneous and 
progressive. In instantaneous nucleation, all the nuclei form at the same time and growth occurs at a slow rate in the further course of time. However, in progressive nucleation both nucleation and growth occur at a fast rate throughout the deposition process. There are several models available to explain this nucleation behaviour through the CA. Equations are used in the form of dimensionless curves where either $\left(I / I_{\mathrm{m}}\right)$ or $\left(I / I_{\mathrm{m}}\right)^{2}$ are plotted against $\left(t / t_{\mathrm{m}}\right)$, where $I_{\mathrm{m}}$ is potentiostatic current maximum and $t_{\mathrm{m}}$ is the corresponding time in CA curve. Of all the models available we have chosen the model given by Bewick et al. [26] and Scharifker and Hills [27] for the analysis of 2D and 3D nucleation mechanism and kinetics, respectively. To plot the theoretical model for $2 \mathrm{D}$ instantaneous and progressive nucleation, Eqs. (1) and (2) are given, respectively [26]:

$$
\begin{gathered}
\frac{I}{I_{\mathrm{m}}}=\frac{t}{t_{\mathrm{m}}} \exp \left[\frac{1}{2}\left\{1-\left(\frac{t}{t_{\mathrm{m}}}\right)^{2}\right\}\right], \\
\frac{I}{I_{\mathrm{m}}}=\left(\frac{t}{t_{\mathrm{m}}}\right)^{2} \exp \left[\frac{2}{3}\left\{1-\left(\frac{t}{t_{\mathrm{m}}}\right)^{3}\right\}\right] .
\end{gathered}
$$

Similarly, for 3D instantaneous and progressive nucleation to plot the theoretical model, Eqs. (3) and (4) are used, respectively [27]:

$$
\begin{aligned}
& \frac{I^{2}}{I_{\mathrm{m}}^{2}}=\frac{1.9542}{\frac{t}{t_{\mathrm{m}}}}\left\{1-\exp \left[-1.2564\left(\frac{t}{t_{\mathrm{m}}}\right)\right]\right\}^{2}, \\
& \frac{I^{2}}{I_{\mathrm{m}}^{2}}=\frac{1.2254}{\frac{t}{t_{\mathrm{m}}}}\left\{1-\exp \left[-2.3367\left(\frac{t^{2}}{t_{\mathrm{m}}^{2}}\right)\right]\right\}^{2} .
\end{aligned}
$$

Nucleation mechanism has been studied in the present investigation by comparing theoretical curves with the experimental data to identify the mode at deposition potential $-1.5 \mathrm{~V}$ for three $\mathrm{Cu}$ concentrations of $0.009,0.012,0.015 \mathrm{M}$, and is shown in Figs. 3a-c, respectively. From the curves of all the respective $\mathrm{Cu}$ concentrations, it is observed that theoretical $2 \mathrm{D}$ and $3 \mathrm{D}$ curves are closely following the same path initially up to the maximum current peak. The observation indicates that new and active nuclei are induced in all the activated nucleation sites at same time. After reaching the maximum, $2 \mathrm{D}$ curves retreat from the view very quickly after forming a monolayer since it is evident from the equations followed where exponential function decreases much faster than their coefficients increase with time. Experimental 2D and 3D curves end up in an elevated plain path; this entire mechanism may be caused due to ensuing formation of new layers successively above the monolayer which
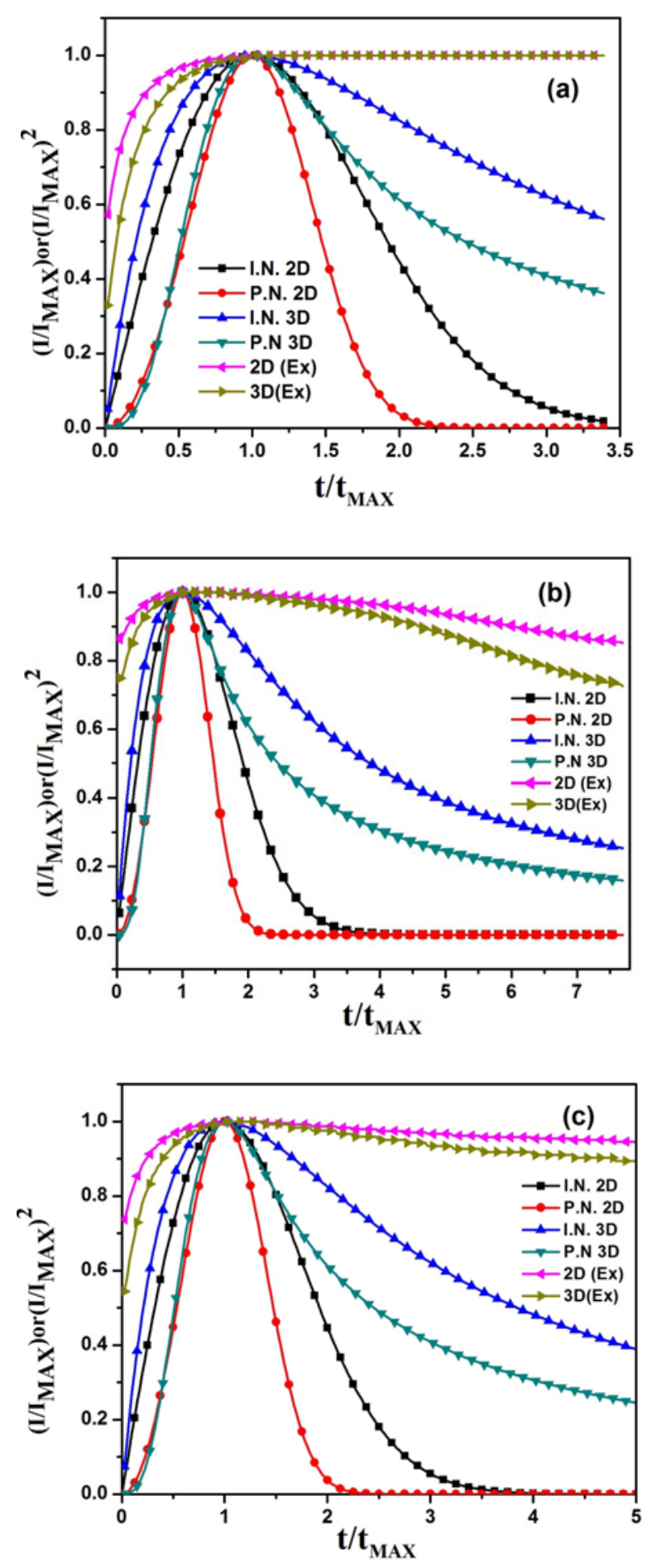

Fig. 3. A comparison of the experimental current transients with theoretical values for both instantaneous and progressive nucleation in a silent deposition at the potential of $-1.5 \mathrm{~V}$ for $2 \mathrm{D}$ and $3 \mathrm{D}$ nucleation at $\mathrm{Cu}$ concentration (a) $0.009 \mathrm{M}$, (b) $0.012 \mathrm{M}$, (c) $0.015 \mathrm{M}$.

prevents current from decreasing. From the modelling analysis, it is obvious to ignore the $2 \mathrm{D}$ curves to interpret the appearance of nucleation sites, whereas con- 
Table 1. Kinetic parameters of $\mathrm{Ni}-\mathrm{Cu}$ alloy thin film deposits from chronoamperometry curve under varying Cu concentration at $-1.5 \mathrm{~V}$ deposition potential

\begin{tabular}{ccccc}
\hline Cu concentration $(\mathrm{M})$ & $I_{\mathrm{M}}\left(10^{2} \mathrm{~A} \mathrm{~cm}^{-1}\right)$ & $T_{\mathrm{M}}(\mathrm{s})$ & $D\left(\mathrm{~cm}^{2} \mathrm{sec}^{-1}\right)$ & $N\left(\mathrm{~cm}^{-2}\right)$ \\
\hline 0.009 & -0.00218 & 5.9 & $2 \times 10^{-11}$ & $2.11 \times 10^{9}$ \\
0.012 & -0.00297 & 2.6 & $3.18 \times 10^{-11}$ & $3.53 \times 10^{9}$ \\
0.015 & -0.0024 & 4 & $3.08 \times 10^{-11}$ & $2.35 \times 10^{9}$ \\
\hline
\end{tabular}
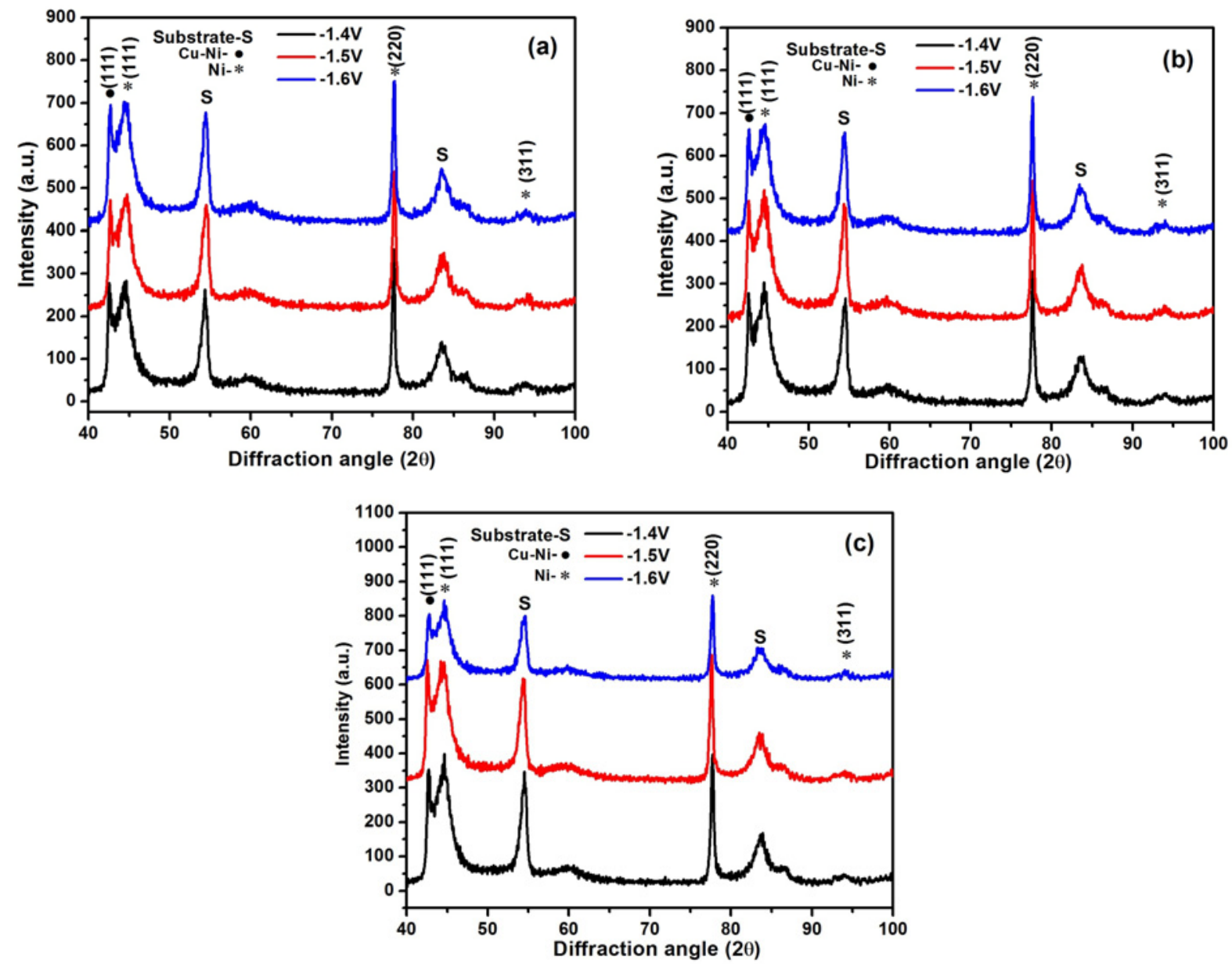

Fig. 4. XRD of Ni-Cu alloy thin films with (a) $0.009 \mathrm{M} \mathrm{Cu}$, (b) $0.012 \mathrm{M} \mathrm{Cu}$, (c) $0.015 \mathrm{M} \mathrm{Cu}$ at different deposition potential at $298 \mathrm{~K}\left(25^{\circ} \mathrm{C}\right)$.

sidering expanded span of time, i.e. $t \geq t_{\mathrm{m}}$ experimental curves are in consensus with the growth mechanism for $3 \mathrm{D}$ instantaneous nucleation followed by diffusion limited growth.

Calculation of diffusion coefficient $D$ and nucleation number density $N$ (Eqs. (5) and (6)) [28] has been done for the Ni-Cu depositions for all the concentrations of $\mathrm{Cu}$ at $0.009,0.012$, and $0.015 \mathrm{M}$ at $-1.5 \mathrm{~V}$, and the results are given in Table 1.

$$
D=\frac{I_{\mathrm{m}}^{2} t_{\mathrm{m}}}{0.1629(z F C)^{2}}
$$

$$
N=\frac{1.2564}{t_{\mathrm{m}} \pi k D}
$$

where $z$ is the number of electrons participating (in this particular case number of electrons are 2), $F$ is the Faraday's constant having value equal to 96500 coulomb, $C$ is the bulk concentration of the reactant in the electrolyte and $k$ is the constant which can be calculated as $\left(\frac{8 \pi C M}{\rho}\right)^{\frac{1}{2}}$, where $\rho$ is the mean density of nickel and copper which is taken as $8.9 \mathrm{~g} \mathrm{~cm}^{-3}$, and $M$ is the mean molecular weight of the nickel and copper (taken as $61.115 \mathrm{~g}$ ). The diffusion coefficient 
Table 2. Crystallite size and lattice strain of $\mathrm{Ni}-\mathrm{Cu}$ alloy films at different $\mathrm{Cu}$ concentrations with varying deposition potential

\begin{tabular}{|c|c|c|c|c|c|c|}
\hline \multirow{2}{*}{ Potential (V) } & \multicolumn{2}{|l|}{$0.009 \mathrm{M} \mathrm{Cu}$} & \multicolumn{2}{|l|}{$0.012 \mathrm{M} \mathrm{Cu}$} & \multicolumn{2}{|l|}{$0.015 \mathrm{M} \mathrm{Cu}$} \\
\hline & Crystallite size (nm) & Strain & Crystallite size (nm) & Strain & Crystallite size (nm) & Strain \\
\hline-1.4 & 267 & 0.024 & 314 & 0.037 & 137 & 0.079 \\
\hline-1.5 & 216 & 0.008 & 298 & 0.047 & 146 & 0.002 \\
\hline-1.6 & 97 & 0.003 & 258 & 0.015 & 98 & 0.008 \\
\hline
\end{tabular}

Ta ble 3. Ni-Cu alloy thin films composition for different $\mathrm{Cu}$ concentrations from EDS

\begin{tabular}{|c|c|c|c|c|c|c|}
\hline \multirow{3}{*}{ Potential (V) } & \multicolumn{6}{|c|}{$\mathrm{Cu}$ concentration } \\
\hline & \multicolumn{2}{|c|}{$0.009 \mathrm{M}$} & \multicolumn{2}{|c|}{$0.012 \mathrm{M}$} & \multicolumn{2}{|c|}{$0.015 \mathrm{M}$} \\
\hline & $\mathrm{Ni}$ (wt.\%) & $\mathrm{Cu}($ wt.\%) & $\mathrm{Ni}(\mathrm{wt} \%)$ & $\mathrm{Cu}($ wt.\%) & $\mathrm{Ni}($ wt.\%) & $\mathrm{Cu}$ (wt.\%) \\
\hline-1.4 & 63 & 37 & 61 & 39 & 59 & 41 \\
\hline-1.5 & 68 & 32 & 66 & 34 & 64 & 36 \\
\hline$-1.6^{6}$ & 74 & 26 & 70 & 30 & 68 & 32 \\
\hline
\end{tabular}

had maximum value for $0.012 \mathrm{M} \mathrm{Cu}$ concentration and again decreased for $0.015 \mathrm{M} \mathrm{Cu}$ concentration, while nucleation number density was calculated highest in the case of $0.012 \mathrm{M} \mathrm{Cu}$ concentration bath with respect to others.

\subsection{X-Ray Diffraction (XRD)}

Figure 4 shows the XRD patterns of Ni-Cu alloy at $0.009,0.012$, and $0.015 \mathrm{M} \mathrm{Cu}$ concentration at different deposition potential on the graphite electrode at $25^{\circ} \mathrm{C}$. The figure shows $\mathrm{Cu}-\mathrm{Ni}$ alloy peaks, $\mathrm{Ni}$ peaks along with the peaks from the substrate material. The alloy film thickness is less than $2 \mu \mathrm{m}$ so that X-ray might have penetrated to the surface more past the coating resulting carbon identification. So the pure phase is not analysed. There is only a single peak of $\mathrm{Cu}-\mathrm{Ni}$ alloy at $2 \theta \approx 44^{\circ}$ which can be indexed as reflection from (111) characteristic plane and various peaks of nickel at $2 \theta \approx 45^{\circ}, 77^{\circ}, 93^{\circ}$ which corresponds to reflection from (111), (220), and (311) characteristic planes, respectively. The crystallite size and lattice strain are calculated by Williamson-Hall formula [28]. The broadening of X-ray line because of particle size and lattice strain of the deposits generates the formula as:

$$
\beta_{\text {total }}=\beta_{\text {particle }}+\beta_{\text {strain }}=\frac{0.94 \lambda}{t \cos \theta}+4 \tan \theta \frac{\Delta d}{d}
$$

The total broadening $\left(\beta_{\text {total }}\right)$ is the measured FWHM in radians, corrected for instrumental broadening. The X-ray wavelength of the source $\mathrm{Cu} \mathrm{K \alpha}$ is $\lambda=$ $0.15418 \mathrm{~nm}$, where $t$ is the particle size, and $4(\Delta d / d)$ represents the strain. Multiplying both sides of the equation by $\cos \theta$ gives the final form, $\beta_{\text {total }} \cos \theta=$ $0.94 \lambda / t+4 \sin \theta(\Delta d / d)$, which is used to calculate the particle size and lattice strain of the separate metal deposit from the plot of $\beta_{\text {total }} \cos \theta$ versus $\sin \theta$.

The values are shown in Table 2 . It can be easily seen that with an increase in negative deposition potential there is a decrease in crystallite size irrespective of $\mathrm{Cu}$ ion concentration in the bath.

\subsection{Scanning electron microscopic (SEM) analysis}

The micrographs of Ni-Cu alloy obtained by electrodeposition from the sulphate bath at $298 \mathrm{~K}\left(25^{\circ} \mathrm{C}\right)$ on the graphite substrate are shown in Fig. 5 .

It is evident from the figure that the deposition is uniform throughout the surface and exhibits a wavelike appearance. The decrease in grain size with increase in deposition potential is clearly evident. Micrographs revealed that deposit morphology was strongly dependent on the deposition potential and $\mathrm{Cu}$ concentration. As the $\mathrm{Cu}$ concentration increases in the electrolytic bath, the deposits are more uniform and dense. Nodular nuclei are formed at $\mathrm{Cu} 0.015 \mathrm{M}$ concentration. The morphology has changed from wavy layered structure to nodular structure with an increase in $\mathrm{Cu}$ concentration. The EDS analysis in Table 3 shows the $\mathrm{Ni}$ and $\mathrm{Cu}$ composition in the bath at a different potential and different $\mathrm{Cu}$ concentration. It can be seen from the table that, for a particular electrolyte bath type, there is a continuous increase of $\mathrm{Ni}$ in the film with an increase in deposition potential [15]. Also, there is a consistent decrease in the wt.\% 

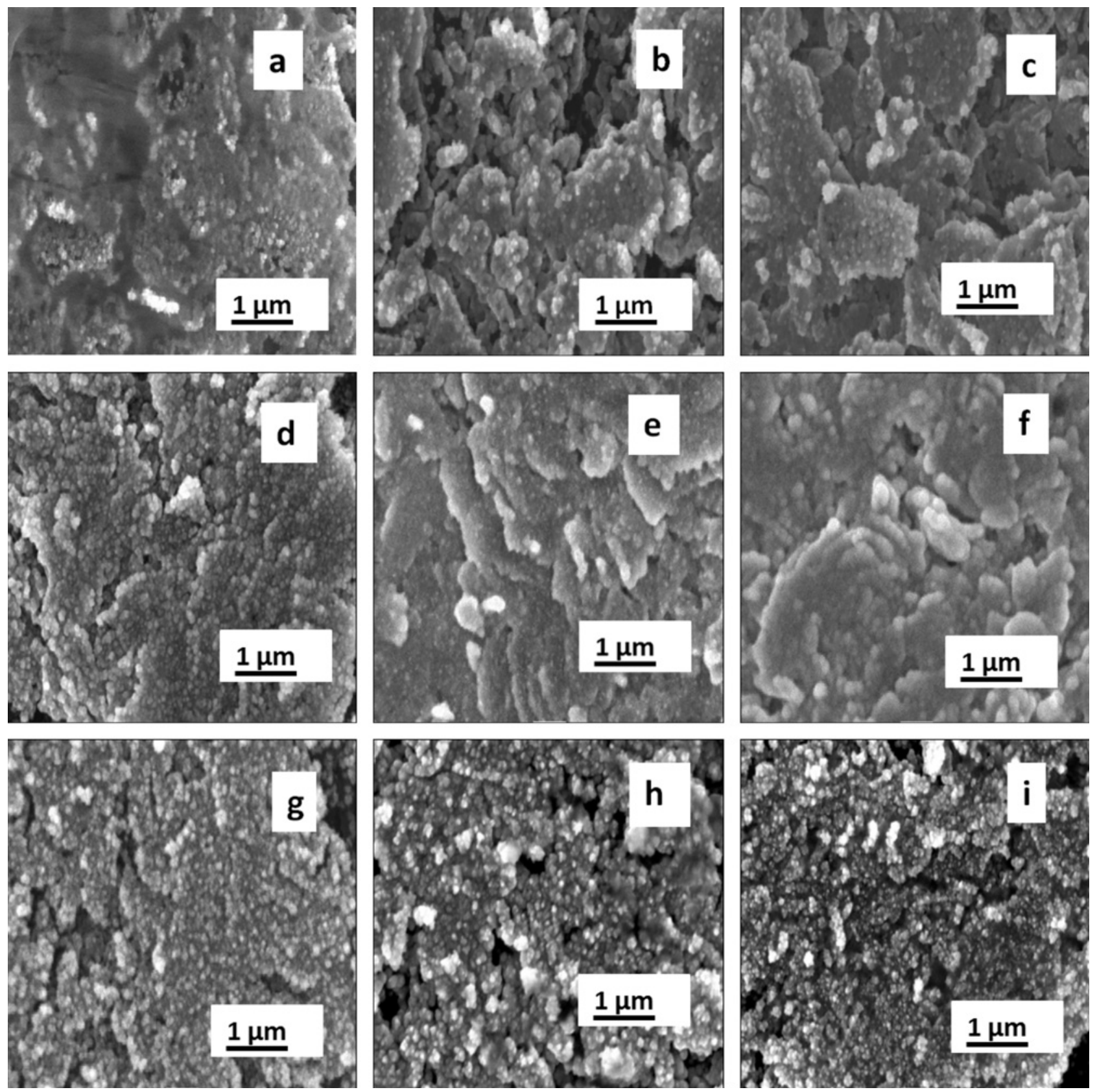

Fig. 5. SEM images of $\mathrm{Ni}-\mathrm{Cu}$ alloy thin films at $\mathrm{Cu}$ concentration $0.009 \mathrm{M}$ at (a) $-1.4 \mathrm{~V}$, (b) $-1.5 \mathrm{~V}$, (c) $-1.6 \mathrm{~V}, 0.012 \mathrm{M}$ at (d) $-1.4 \mathrm{~V},(\mathrm{e})-1.5 \mathrm{~V},(\mathrm{f})-1.6 \mathrm{~V}$, and $0.015 \mathrm{M}$ at $(\mathrm{g})-1.4 \mathrm{~V},(\mathrm{~h})-1.5 \mathrm{~V},(\mathrm{i})-1.6 \mathrm{~V}$.

of $\mathrm{Ni}$ in the film with an increase in the $\mathrm{Cu}$ ion concentration (decrease in $\mathrm{Ni}$ ion concentration) in the electrolyte bath $(0.009$ to $0.015 \mathrm{M})$ for a particular deposition potential [10]. Impurities like $\mathrm{S}$ and $\mathrm{O}$ in the film are neglected and not mentioned in the table since these are present in some minor amount.

\subsection{Roughness analysis}

The roughness of the deposited $\mathrm{Cu}-\mathrm{Ni}$ alloy thin films was measured by AFM by performing line scan at various sections of the deposited film. Experimental values like distribution of grains, roughness, and the average height of the films are summarized in Table 4. It is well known from the various literature that roughness of the deposited film increases with an increase in $\mathrm{Cu}$ content of the film $[18,19]$. However, no such relationship was observed in the present study. For a particular bath type $(0.009 \mathrm{M} \mathrm{Cu})$ the grain size was continuously decreasing with an increase in deposition potential. Whereas for a constant deposition potential $(-1.6 \mathrm{~V})$ there is an increase in the grain size with an increase in the $\mathrm{Cu}$ content in the electrolyte bath $(0.009$ to $0.015 \mathrm{M} \mathrm{Cu})$. The average height is vary- 
Ta ble 4. Roughness factor and grain size distribution of Ni-Cu alloy film from MFM topographic measurement

\begin{tabular}{ccccc}
\hline Concentration (M) & Potential (V) & Grain size distribution (nm) & Roughness factor (nm) & Average height (nm) \\
\hline \multirow{2}{*}{0.009} & -1.4 & $129-419$ & 129 & 445 \\
& -1.5 & $115-395$ & 219 & 776 \\
& -1.6 & $96-315$ & 120 & 610 \\
\hline 0.012 & -1.6 & $246-279$ & 169 & 768 \\
\hline 0.015 & -1.6 & $261-379$ & 139 & 610 \\
\hline
\end{tabular}
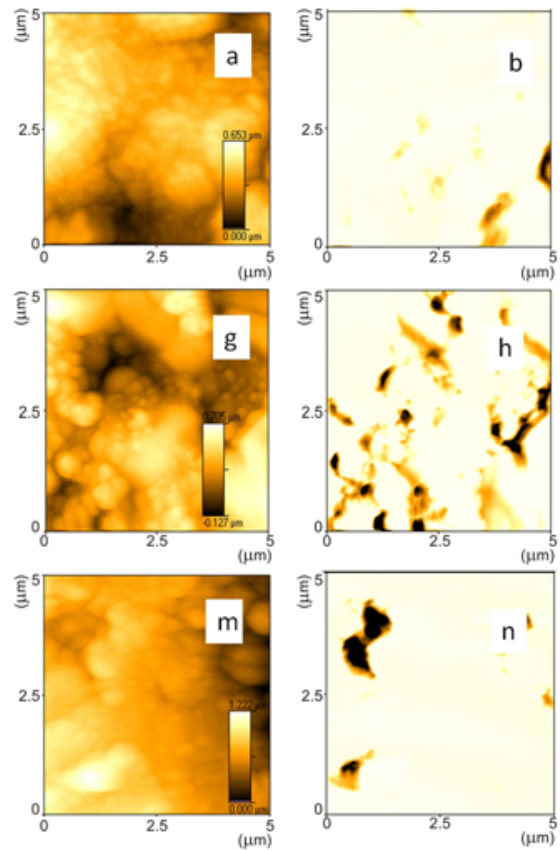
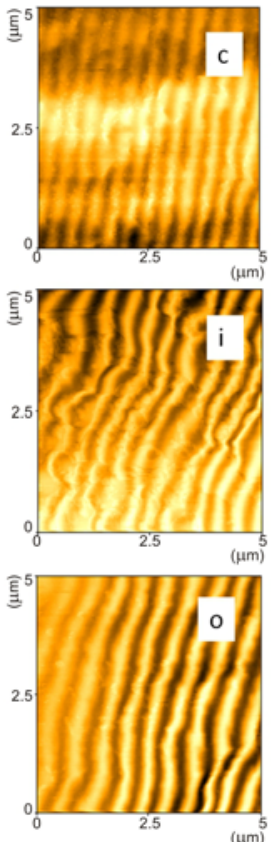
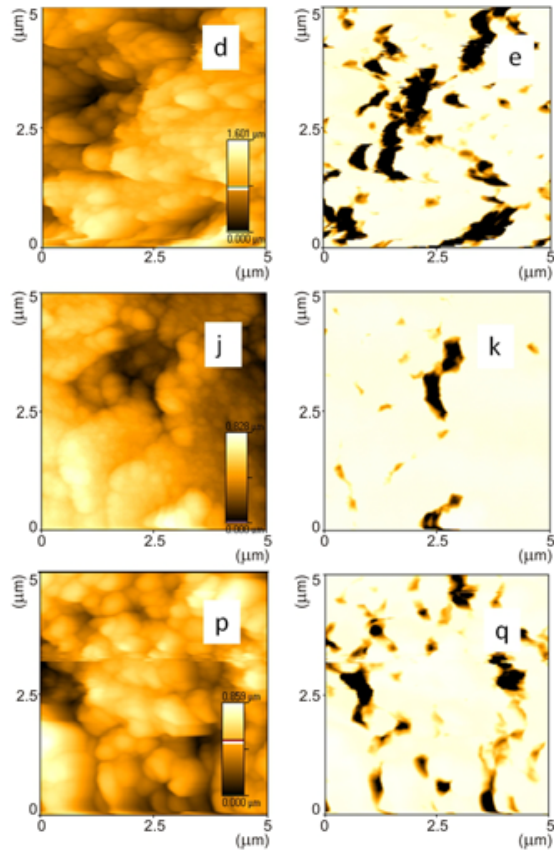
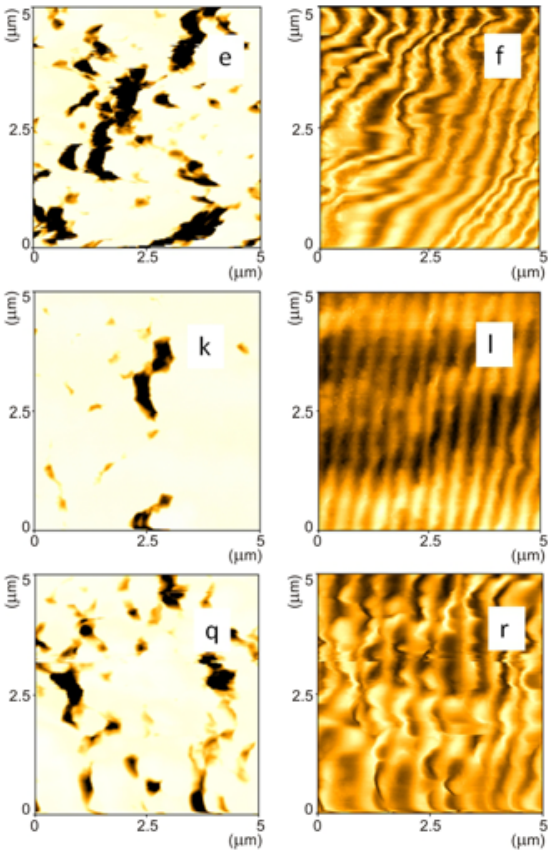

Fig. 6. MFM images of Ni films deposited at $-1.4 \mathrm{~V}(\mathrm{a}-\mathrm{c})$, Cu-Ni films deposited at $-1.4 \mathrm{~V}$ and $0.015 \mathrm{M} \mathrm{Cu}(\mathrm{d}-\mathrm{f})$, at $-1.5 \mathrm{~V}$ and $0.015 \mathrm{M} \mathrm{Cu}(\mathrm{g}-\mathrm{i})$, at $-1.6 \mathrm{~V}$ and $0.015 \mathrm{M} \mathrm{Cu}(\mathrm{j}-\mathrm{l})$, at $-1.6 \mathrm{~V}$ and $0.012 \mathrm{M} \mathrm{Cu}(\mathrm{m}-\mathrm{o})$, and at $-1.6 \mathrm{~V}$ and $0.009 \mathrm{M} \mathrm{Cu}$ $(\mathrm{p}-\mathrm{r})$.

ing within a range of 429-768 nm for $\mathrm{Cu}-\mathrm{Ni}$ films deposited from different electrolyte bath with different potential.

\subsection{Magnetic phase characterization}

To thoroughly understand and investigate the magnetization behaviour of the co-deposited diamagnetic-ferromagnetic $\mathrm{Cu}-\mathrm{Ni}$ alloy thin films, a qualitative analysis has been performed by using the MFM as shown in Fig. 6. The coercivity (both in-plane and perpendicular) of the $\mathrm{Sb}(\mathrm{n})$ doped $\mathrm{Si}$ tip coated with $\mathrm{Co} / \mathrm{Cr} / \mathrm{BOT}-1-10 \mathrm{~nm} \mathrm{Cr}$ on both sides is $\sim 950 \mathrm{Oe}$. Hence the magnetic phases present in the film are expected to have been fully magnetized during the scanning. For comparison, the topographic, as well as MFM images of Ni are also presented in Fig. 6 along with the images of thin films under different conditions. The topographic micrographs indicate the presence of aggregates of different sizes on the electrode surface. It can be found from the figure that the $\mathrm{Ni}$ deposit is the finest as compared to the alloy films.

The amplitude mode MFM images of the sample can be clearly observed in Fig. 6. The scan height was set at $50 \mathrm{~nm}$. The applied AC peak voltage $\left(V_{\mathrm{p}}\right)$ to the sample is $4.8 \mathrm{~V}$ with a frequency of $67 \mathrm{kHz}$. It can be observed clearly that there are many bright areas in the amplitude image (Fig. 6b). The amplitude signal is always positive. Here, the bright area has the large AC magnetic field, while the dark area has a value near zero for the AC magnetic field. Therefore, the bright areas should be corresponding to the magnetic phase of the films and the dark areas may be the nonmagnetic phase present therein. The analysis further supports to the logic as it can be observed that, the phase has almost $95 \%$ bright phase which has been magnetized because of the interaction with the high magnetic field. Due to the incorporation of copper into the Ni films, the magnetic phases were found to be reduced/altered in a synchronized fashion as that of the 
Ni composition in the film (see Table 3 ). At a particular $\mathrm{Cu}$ concentration $(0.015 \mathrm{M})$, with an increase of deposition potential, the percentage of bright phase was found to be increased and hence the degree of magnetization which is well expected and accepted (Figs. 6e,h,k).

Now, considering the dipole moment system in the films, bright and dark stripe-like regions in the image (Fig. 6) can be observed prominently for $\mathrm{Ni}$ as well as alloy films. The phase image is used for the domain dipole contrast studies. However, in our case, the phase contrast images are less informative (not shown here). Hence the TM deflection images were used which were also due to the phase shift of the cantilever at certain lift height from the surface. Also for continuous films or bulk magnetic materials deflection images are much more informative. The alternative stripe patterns are caused by the out-of-plane magnetic domains separated by the $180 \mathrm{deg}$ domain walls; the dark part is visible because of low resolution. Large negative shifts in the resonance frequency are black, and large positive shifts in the resonance frequency are white. Alternatively, the peaks and valleys represent the magnetic flux generated from the northand south-pole transitions, respectively. It can be observed from the figures that $\mathrm{Ni}$ being in the ferromagnetic materials has a very systematic pattern of stripe domains with a width of $0.45 \mu \mathrm{m}$. However, when copper is incorporated, the patterns get disturbed and thickened. At lower copper concentration and higher deposition potential, we observe much more intense and localized magnetic domains of uniform size.

\section{Conclusions}

$\mathrm{Ni}-\mathrm{Cu}$ magnetic alloy thin films were cathodically electroplated onto graphite electrodes at various over-potentials and different $\mathrm{Cu}$ concentrations. Cyclic voltammograms (CV) and chronoamperometry (CA) were performed in different potential range to set the deposition potential and identify the mode of electrodeposition process. There is a significant increase in the maximum reduction current with increasing $\mathrm{Cu}$ concentration in the electrodeposition alloy bath. For $\mathrm{Ni}-\mathrm{Cu}$ alloy, nucleation time was shorter for high negative potential and low $\mathrm{Cu}$ concentration. Also, the mode of nucleation was 3D type irrespective of deposition potential and composition of the depositing bath. The phases of the deposits are confirmed by the XRD analysis. Lattice strain and crystallite size were increased and decreased with deposition overpotential, respectively. Surface morphology and microstructure show passable dependence on the deposition potential and concentration of the bath. EDS analysis for $\mathrm{Ni}-\mathrm{Cu}$ alloy confirms that as the potential increases and $\mathrm{Cu}$ concentration decreases, the films get richer in
Ni. Magnetic microstructure (MFM) analysis demonstrates that the magnetic domain structure is better for $\mathrm{Ni}-\mathrm{Cu}$ alloy deposits at lower $\mathrm{Cu}$ concentration and high deposition potential.

\section{Acknowledgements}

The authors would like to thank the National Institute of Technology (NIT) Rourkela, the Council of Scientific and Industrial Research (CSIR), India under the scheme 22/611/12/EMR-II, and the Department of Science and Technology India (No. SR/FTP/ETA-36/2011), for providing necessary financial and infrastructural support for this research work.

\section{References}

[1] Mehrizi, S., Sohi, M. H., Seyyed Ebrahimi, S. A.: Surf. Coatings Technol., 205, 2011, p. 4757. doi:10.1016/i.surfcoat.2011.03.070

[2] Gyorgy, E., McWhan, D., Dillon, J., Walker, L.,Waszczak, J.: Phys. Rev., 25, 1982, p. 6739. doi:10.1103/PhysRevB.25.6739

[3] Pattanaik, G., Kirkwood, D. M., Xu, X., Zangari, G.: Electrochim. Acta, 52, 2007, p. 2755. doi:10.1016/j.electacta.2006.07.062

[4] Osaka, T., Asahi, T., Kawaji, J.,Yokoshima, T.: Electrochim. Acta, 50, 2005, p. 4576. doi:10.1016/j.electacta.2004.10.099

[5] Osaka, T.: Electrochim. Acta, 45, 2000, p. 3311. doi:10.1016/S0013-4686(00)00407-2

[6] Freeman, A. J., Wu, R. Q.: J. Magn. Magn. Mater., 104, 1992, p. 1. doi:10.1016/0304-8853(92)90677-G

[7] Singh, R.: J. Magn. Magn. Mater., 346, 2013, p. 58. doi:10.1016/j.jmmm.2013.07.005

[8] Alper, M., Kockar, H., Safak, M., Baykul, M. C.: J. Alloy. Compd., 453, 2008, p. 15. doi:10.1016/j.jallcom.2006.11.066

[9] Baskaran, I., Narayanan, T. S. N. S., Stephen, A.: Mater. Lett., 60, 2006, p. 1990. doi:10.1016/j.matlet.2005.12.065

[10] Goranova, D., Avdeev, G., Rashkov, R.: Surf. Coatings Technol., 240, 2014, p. 204. doi:10.1016/i.surfcoat.2013.12.014

[11] Uhlemann, M., Geber, A., Herrich, M., Krause, A., Cziraki, A., Schultz, L.: Electrochim. Acta, 48, 2003, p. 3005. doi:10.1016/S0013-4686(03)00366-9

[12] Brett, C. M. O., Brett, A. M. O.: Electrochemistry: Principles, Methods and Applications. Oxford, Oxford University Press 1994.

[13] Erb, U.: Nanostruct. Mater., 6, 1995, p. 533. doi:10.1016/0965-9773(95)00114-X

[14] Agarwal, M., Kumar, V., Malladi, S. R. K., Balasubramaniam, R., Balani, K.: Journal of Minerals, Metals \& Materials Society, 62, 2010, p. 88. doi:10.1007/s11837-010-0095-6

[15] Sarac, U., Oksuzoglu, R. M., Baykul, M. C.: J. Mater. Sci.: Mater. Electron., 23, 2012, p. 2110. doi:10.1007/s10854-012-0709-6

[16] Pellicer, E., Varea, A., Pane, S., Nelson, B. J., Menendez, E., Estrader, M., Surinach, S., Baro, M. D., 
Nogues, J., Sort, J.: Adv. Funct. Mater., 20, 2010, p. 983. doi:10.1002/adfm.200901732

[17] Alper, M., Baykul, M. C., Peter, L., Toth, J., Bakonyi, I.: J. App. Electrochem., 34, 2004, p. 841. doi:10.1023/b:jach.0000035608.49948

[18] Haciismailoglu, M., Alper, M.: Surf. Coatings Technol., 206, 2011, p. 1430. doi:10.1016/j.surfcoat.2011.09.010

[19] Varea, A., Pellicer, E., Pane, S., Nelson, B. J., Surinach, S., Baro, M. D., Sort, J.: Int. J. Electrochem. Sci., 7, 2012, p. 1288.

[20] Lu, W., Jia, M., Ling, M., Xu, Y., Shi, J., Fang, X., Song, Y., Li, X.: J. Alloys Compd., 637, 2015, p. 552. doi:10.1016/i.jallcom.2015.03.036

[21] Davar, F., Fereshteh, Z., Salavati-Niasari, M.: J. Alloys Compd., 476, 2009, p. 797.

doi:10.1016/j.jallcom.2008.09.121
[22] Pandey, B., Das, D., Kar, A. K.: Appl. Surf. Sci., 337, 2015, p. 195. doi:10.1016/i.apsusc.2015.02.092

[23] Pavithra, G. P., Hegde, A. C.: Appl. Surf. Sci., 258, 2012, p. 6884. doi:10.1016/i.apsusc.2012.03.124

[24] Das, A., Mallik, A., Ray, B. C.: Metall. Mater. Trans., 43, 2012, p. 267. doi:10.1007/s11663-011-9593-3

[25] Mallik, A.: Trans. Indian Inst. Met., 66, 2013, p. 79. doi:10.1007/s12666-012-0229-3

[26] Bewick, A., Fleischmann, M., Thirsk, H. R.: Trans. Faraday Soc., 58, 1962, p. 2200. doi:10.1039/TF9625802200

[27] Scharifker, B., Hills, G.: Electrochim. Acta, 28, 1983, p. 879. doi:10.1016/0013-4686(83)85163-9

[28] Williamson, G. K., Hall, W. H.: Acta Metall., 1, 1953, p. 22. doi:10.1016/0001-6160(53)90006-6 